JOURNAL REVIEW

\section{Termination of pregnancy as emergency obstetric care: the interpretation of Catholic health policy and the consequences for pregnant women}

Berer M. Reprod Health Matters 2013;21: 9-17

This paper presents an analysis of several cases from Ireland, the USA and South America where interpretation of what the author terms "Catholic health policy" has resulted in deaths of pregnant women; deaths that could have been averted if the women had been able to have the termination of pregnancy (TOP) that they were requesting.

Data used in the analysis were publically available and mostly from media reports. In most of the cases, TOP could have legally taken place for what the author terms "emergency obstetric care" to save the mother's life. The author highlights common themes in the cases that relate to predominantly Catholic countries or hospitals linked to the Catholic Church. One commonality is that the conditions/circumstances that are considered to be putting women's lives at risk are impossible to define, and also how close to death a women should be (by which time a TOP may be too late). Another common theme is that of fear among clinicians that prevents them from becoming involved. Fear of being accused of having conducted an illegal TOP and of possible loss of job or imprisonment, so that the woman is advised to travel to a country where TOP can be performed, or else leads to the death of the pregnant woman who is denied a TOP.

A further common theme is that these countries or hospitals concerned had existing guidance produced by the Catholic Church concerning TOP for preventing maternal death, but that this guidance is open to quite varying interpretation both between and within countries.

One criticism of the article is that the clinician may find the author's use of the term 'non-viable' (used to infer an unrealistic likelihood of the baby surviving) confusing since clinicians use this term strictly to signify that no fetal heart beat is present.
The article is topical since Ireland and Northern Ireland have been reviewing guidance on conditions under which TOP can be legally performed. If these governments can learn from the cases in this article then they would be advised to issue clear guidance that the decision to proceed to TOP should be a clinical one and should be able to be taken quickly. In particular, the necessity to involve a committee of professionals with its inherent delays should be avoided. The clinicians caring for the woman should not feel that they will in any way be subject to dismissal, loss of professional esteem, or be subject to legal action or even imprisonment.

\section{Reviewed by Sharon Cameron}

Consultant Gynaecologist, Chalmers Sexual and Reproductive Health Centre, Edinburgh, UK

Competing interests The author has received funding from Pfizer for research with Depo-Provera ${ }^{\circledR}$.

Provenance and peer review Commissioned; internally peer reviewed.

J Fam Plann Reprod Health Care 2013;39:284. doi:10.1136/jprhc-2013-100741 